\title{
"ОБЩЕЕВРОПЕЙСКИЙ ДОМ" И ЕВРОПЕЙСКОЕ ПРАВОВОЕ IIPOCTPAHCTBO
}

\section{И.А. Смирнов *}

Понятие "общеевропейский дом" введено в международное право советско-французским Договором о согласии и сотрудничестве от 29 октября 1990 г., в котором указывается, что стороны "будут содействовать укреплению между собой и всеми европейскими государствами уз солидарности, ведущих $к$ превращению ее в обший дом и к созданию европейской конфедерации" (ст.2). Вслед за тем и советско-германский Договор о добрососедстве, партнерстве и сотрудничестве от 9 ноября 1990 г. провозглашает цель обеих сторон "превращение Европы в единое пространство права, демократии и сотрудничества в области экономики, культуры и информации" (ст.5). Все более широкое употребление этих новых понятий ставит вопрос об их юридической квалификации, их содержании, соотношении с международно-правовыми нормами и институтами.

Сколь бы новой ни казалась идея "общеевропейского дома" как некоего объединения европейских государств, она уходит корнями в глубь веков. Основы этой идеи разрабатывались такими мыслителями, как П. Дюбуа, Марини, Сюлли, У. Пенн, аббат СенПьер, Ж.Ж. Руссо, И. Бентам. Вершиной "организованного пацифизма" считается учение И. Канта о вечном мире, поскольку он первым "высказал догадку об объективной закономерности, ведущей к установлению мира, о неизбежности создания на мирных началах союза народов" ". Вечный мир для И. Канта - не некий единовременно устанавливаемый порядок, а цель, к которой можно приближатъся путем активного и постоянного сотрудничества государств. Представляется, что без учета этих идей вряд ли возможен концептуальный анализ понятия "общеевропейский дом".

При первом же подходе к проблеме обращает на себя внимание терминологическая новелла - "дом", "пространство". Означает ли это, что создатели "дома" стремятся к установлению такого правового порядка в Европе, который невозможно определить в существующих понятиях и категориях международного права (институционный аспект)? Или же имеется в виду нынешнее неудовлетворительное состояние дел в Европе и, как следствие, ставится цель качественно его изменить без указания конкретных способов такого изменения (телеологический аспект)?

\footnotetext{
*Аспирант кафедры международного права МГИМО МИД РФ.
} 
На наш взгляд, "общий дом" - не определенный status quo, а политическая цель, для достижения которой используются различные средства, включая международно-правовые. Именно исследование последних может дать содержательное описание категории "общего дома" с точки зрения международного права.

Вернемся к приведенному выше положению советско-французского договора. Обращает на себя внимание то, что он не содержит какого-либо изложения позиций сторон относительно содержания понятия "обший дом". В статъе 3 лишь перечисляются основные принципы будущего европейского порядка, которые по преимуществу являются нормами jus cogens, закрепленными в Уставе ООН. В этой связи остается неясной качественная специфика "общеевропейского дома" с точки зрения международного права.

Наряду с "общим домом" в статье 2 упоминается и "европейская конфедерация". Хотя последняя является сложившимся междунаропно-правовым понятием, тот факт, что договор не раскрывает ее содержания применительно к Европе, а также как бы ставит ее на один уровень с "обшим домом", подводит к мысли о том, что оба государства не имели намерения описьвать будуший европейский порядок в юридических категориях и рассматривают как "общий дом", так и "конфедерацию" в качестве политической цели.

Обратимся теперь к понятию "европейское правовое пространство", впервые примененному на Парижском совешании Конференции по человеческому измерению СБСЕ в 1989 году. Это понятие обычно рассматривается как юридическая конкретизация термина "обший дом". Само по себе использвание нового термина подразумевает наличие самостоятельного явления международной жизни, представляющего собой самовоспроизводящуюся систему отношений, элементов, объединенных необходимыми правовыми связями. Преобладающая в отечественной литературе по международному праву точка зрения, согласно которой европейское правовое пространство является сообществом правовых государств ${ }^{2}$, не дает ответа на вопрос о правовой природе системообразующих факторов такого сообщества. По нашему мнению, главными факторами такого рода являются международные договоры и юридически обязатепные решения международных организаций. Иными словами, необходимым условием формирования европейского правового пространства является согласование вољь субъектов международного права относительо юридически обязательных унифицированных правил поведения в той или иной области.

Европейское правовое пространство, по определению, является сферой действия правовых норм. Последние оформляют фактические отношения, сложившиеся между субъектами этих отношений. Евро- 
пейское правовое прсстранство не является совокупностью национальных правовых систем, поскольку каждая из них действует в пределах национальных границ. Использование в качестве критерия категории "правовое государство" нацелено на исследование правовой системы той или иной конкретной страны и уже поэтому вряд ли подходит для выявления качественной специфики европейского правового пространства.

Если правовые системы государств - членов Совета Европы обеспечивают единый уровень защиты прав человека, то это происходит благодаря участию в международном договоре - Европейской конвенции о зашите прав человека и основных свобод. Главным побудительным мотивом унификации национального законодательства, без которой немыслимо европейское правовое пространство, является заключение многосторонних международных договоров в различных областях.

Практика показывает, что наиболее эффективной является унификация на основе договоров, заключенных в рамках международных организаций или на основании решений органов таких организаций (Совет Европы, Европейские сообщества). В этих условиях заключение договоров утрачивает спорадический характер и становится системой, направленной на максимальное сближение законодательтва государств с целю создания экономического и политического союза. Таким образом, институциализация межгосударственных отношений на континенте является главным фактором создания "единой Европы".

В этой связи нелъзя не отметить роль Совещания по безопасности и сотрудничеству в Европе. Его уникальность двояка: во-первых, это единственный форум, объединяющий все европейские государства; во-вторых, круг вопросов, входящих в сферу рассмотрения СБСЕ, чрезвычайно широк. Вследствие этого именно СБСЕ может стать несущей конструкцией "общеевропейского дома". Но для этого по менъшей мере необходимо, чтобы документы Совещания носили характер международных договоров, а не только политических обязательств, хотя бы и тщатељно разработанных.

Несмотря на то что документы СБСЕ не являются источниками международного права, государства стремятся максимально задействовать потенциал Совещания, принимая на себя юридические обязательства, в частности посредством включения соответствуюших положений в двусторонние договоры. Так, советско-германский договор от 9 ноября 1990 г. содержит положение о том, что "обе стороны будут оказывать всемерное содействие развитию процесса безопасности и сотрудничества в Европе на основе Заключительного акта Хельсинки от 1 августа 1975 года" (ст.5). Аналогич- 
ные нормы содержатся также в Договоре о дружбе и сотрудничестве между СССР и Италией от 18 ноября 1990 г. (ст. 3-4), в Договоре о дружбе и сотрудничестве между СССР и Испанией от 9 июля $1991 \mathrm{r}$. (ст.1) и в ряде других документов.

Высказывается мнение, что надежным гарантом соблюдения договоренностей, зафиксированных в документах СБСЕ, мог бы стать специально созданный для этой цели судебный орган или, в качестве паллиативного решения, существуюшие европейские суды $^{3}$. Но главным условием осуществимости этой идеи является юридизация хельсинкского процесса. Действительно, суд может рассматривать дела и принимать обязательные решения, основываясь на источниках права, в число которых акты СБСЕ не входят. С другой стороны, использование существующих судебных органов невозможно ввиду того, что они действуют в рамках международных организаций - самостоятельных субъектов международного права и рассматривают дела, касающиеся лишь их членов, на основе учредительных актов этих организаций. Передача в такие суды вопросов относительо реализации положений, содержашихся в документах СБСЕ, возможна только на основании договора между европейскими организациями и СБСЕ. Поскольку ни Совещание в целом, ни его постоянные органы, созданные в соответствии с Парижской хартией для новой Европы в ноябре 1990 года, не обладают международной правосубъектностью, заключение такого договора на данном этапе не представляется возможным.

Итак, для эффективного взаимодействия СБСЕ и региональных и универсальных организаций недостаточно придать юридически обязатељный характер актам Совещания. Совещание само должно статъ субъектом международного права - международной организацией. Органы СБСЕ, созданные в соответствии с Парижской хартией, такие как Парламентская ассамблея СБСЕ, Бюро по свободным выборам, Совет министров иностранных дел, Комитет старших должностных лиц, Центр по предотвращению конфликтов и др., наделены лишь консультативными функциями. В частности, подчеркивается, что заседания совета будут являться "центральным форумом для попитических консультаций" в рамках СБСЕ. Представляется вместе с тем, что, несмотря на столь ограниченные на сегодняшний день полномочия, эти органы впоследствии могут стать базой преобразования СБСЕ в международную организацию, основанную на народном представительстве, с законодательным, исполнительным и судебным органами.

Для этого предположения есть некоторые основания, в частности то, что Парижская хартия рассматривает Европу как "единое целое". Точнее было бы сказать, что она будет "единым целым" 
в случае реализации возможностей СБСЕ по созданию представительной системы. К этой мысли подводит и то соображение, что суд не может быть единственным органом СБСЕ, принимающим юридически обязательные решения. Лишь совместное функционирование всех институтов демократического правления способно обеспечить максимально эффективную реализацию актов СБСЕ. По нашему мнению, глубина и тщательность проработки взаимных обязательств в рамках Совещания, а также учреждение постоянных органов свидетельствуют о том, что хельсинкский процесс вплотную подошел К новой качественной ступени своего развития.

Юридизация СБСЕ - не единственный путь строительства "обшеевропейского дома". Есть и иной вариант, связанный с утверждением в качестве центра и ориентира общеевропейской интеграции Европейских сообществ (EC). Более того, этот вариант в настоящее время является наиболее реальным. Действительно, достижение целей Единого европейского акта позволит создать на Западе Европы уникальный экономический, политический и правовой союз. Особенностью ЕС являются сопоставимый уровенъ экономического развития и близость фундаментальных интересов участвуюших в них государств, что и делает возможным такой союз. На достижение этого уровня направлены усилия многих европейских стран. Подтотовка договора между ЕС и ЕАСТ о создании общего экономического пространства (и́ шире - вся история отношений ЕС - ЕАСТ), официальные заявки некоторых западноевропейских стран на вступление в ЕС (Австрия, Кипр, Мальта, Швеция, Турция), ассоциированное членство Венгрии, Польши и पехо-Словакии в ЕС являются свидетельствами преобладающей тенденции в Европе. В этих условиях формирование европейского правового пространства означает распространение действия норм "европейского права" на другие государства.

पем объясняется ведущая роль ЕС в создании "новой Европы"? В отличие от СБСЕ и Совета Европы - механизмов, занимающихся преимущественно гуманитарными вопросами, - ЕС ставит своей целью интеграцию прежде всего базисных общественных отношенийэкономических. Преамбула Римского договора выражает стремление ЕЭС "заложить основы еще более тесного союза между народами Европы". Из этого следуют, по крайней мере, два вывода: во-первых, экономическая интеграция не является самоцелью, а выступает основой "более тесного союза" в конечном счете с политической ориентацией. Во-вторых, "союз между народами" не равнознаqен "союзу между государствами". В первом случае присутствует намерение осуществлять интеграционные процессы не только на правительственном, но и на неправительственном уровне. В этой связи нељзя не отметить, что субъектами права ЕС являются не только государ- 
ства-члены, то есть субъекты международного права, но и юридические и физические лица. Этот факт объясняется прежде всего нацеленностью стран-членов ЕС на создание единого внутреннего рынка, в котором одну из ведущих ролей будут играть субъекты гражданского права. Сближение законодательства, в том числе и гражданского, - одно из основных направлений деятельности ЕC (п. h ст.3; ст.100 Римского договора). Это, в свою очередь, делает не только возможным, но и необходимым создание на новой экономической основе политического союза с чертами национального государства (система разделения властей).

ЕС характеризуется высокой степеңњю автономности центральных учреждений сообществ по отношению к национальным правительствам. "Наднациональный характер" сообществ подчеркивается в статъе 9 Парижского договора об учреждении Европейского объединения угля и стали от 18 апреля 1951 г. Принципиальная важность этого положения подтверждается тем фактом, что в ноте от 25 мая 1950 г. Робер IІуман, министр иностранных дел Франции, автор известной декларации 9 мая 1950 г., настаивал на том, чтобы еще до начала переговоров об образовании ЕОУС государства в приншипе согласились с созданием наднационального органа ${ }^{4}$.

Подобная самостоятельност учреждений сообществ и характер принимаемых ими решений позволяют говорить о "европейском праве" 12 государств, основанном на специфических принципах. На наш взгляд, именно появление общеевропейских правовых принципов в процессе строительства европейского единства, подобно принципам, выработанным Судом $\mathrm{EC}^{5}$ (верховенство и прямое действие права сообществ, принцип всемерной защиты прав человека и основных свобод и др.), явится свидетельтвом возниқновения европейского правового пространства. Как мы уже показали, наиболее вероятный путь к этому - расширение состава ЕС.

Однако нељзя не отметить фундаментальную ограниченность нынешней правовой системы ЕС как основы "общеевропейского дома". Она заключается в противоречии между правовой природой Европарламента как органа, представляющего население 12 стран $^{6}$, и природой совета, представляющего государства. Следовательно, постановления, директивы и решения совета, являясь так называемым вторичным законодательством ЕС, по сути близки к международным договорам и отличаются от них лишь тем, что не подлежат ратификации. Такое положение оправданно лишь в той мере, в какой Европарламент лишен законодательных полномочий. Придание их ему с неизбежностью поставит в перспективе вопрос о формировании исполнительных органов Сообщества, подотчетных парламенту. Тенденции и этапы развития ЕС, в частности Брюссельский договор 
о слиянии руководящих органов трех сообществ от 8 апреля 1965 г., введение в 1979 году прямых выборов в Европарламент, заключение договоров о политическом и валютно-экономическом союзе (декабрь 1991 г.), подтверждают нацеленность сообществ на создание .в итоге представительнй системы.

Наряду с отмеченными явлениями набирает силу тенденция к федерализации общественных отношений в Европе. Это связано прежде всего с усилением активности субъектов европейских федераций 7 и процессов федерализации в некоторых унитарных государствах (например, в Бельгии) ${ }^{8}$. Важными этапами на этом пути стали мюнхенская (октябрь 1989 г.) и брюссельская (апрель 1990 г.) конференции "Европа регионов", причем инициатива их проведения принадлежит федеральной земле Бавария.

पем объясняется повышение роли регионов в европейском строительтве? По нашему мнению, здесь имеется по менъшей мере два ряда причин. С одной стороны, субъекты федераций (в данном случае - земли ФРГ, поскольку Германия - единственное федеративное государство в ЕС) справедливо полагают, что действитељно демократическое принятие решений в ЕС невозможно без учета их мнения, так как в конечном счете основная работа по выполнению этих решений ложится на земли. По этой причине земли стремятся институциализировать свое представительство в ЕС в виде создания особого органа (разумеется, в него вошли бы представители не только земель ФРГ, но и региональных образований других стран). Необходимость создания такого органа подтвердила мюнхенская конференция "Европа регионов". С другой стороны, регионы, не являющиеся субъектами федераций (Уэльс, ІІотландия, Страна Басков и др.), считают свой правовой статус неадекватным растущему национальному самосознанию и рассматривают это как угрозу демократии и правам человека. В этих условиях гарантом демократии, по их мнению, призвана стать федерализация государственного устройства таких стран.

Повышение активности регионов, увеличение числа прямых межрегиональных связей - объективньй процесс. Вероятно, он окажет свое влияние на облик Европы в обозримом будущем. В этой связи В.В. Пустогаров заметил, что "перспектива строительства общего дома на континенте состоит в федерализации, а не в усилении унитарности"9.

Вместе с тем, на наш взгляд, не следует и переоценивать роль регионов в европейской интеграции. Видимо, активизация их деятельности связана именно с незначительностью этой роли. Так, пункт 1 статьи 32 Основного закона ФРГ 1949 года четко определяет, что "ведение сношений с иностранными государствами принадлежит 
Федерации". Земли могут заключать договоры с иностранными государствами лишь с согласия федерального правительства и в пределах своей компетенции.

Применительно к европейской интеграции следует отметить, что земли ФРГ не имеют собственного статуса по праву ЕС. Передача суверенных прав в пользу центральных учреждений $\mathrm{EC}$ осуществляется на основе пункта 1 статъи 24 Основного закона: "Федерация может законодательным путем передавать верховную власть межгосударственным установлениям". В случае возникновения разногласий между бундестагом и бундесратом, органом представительства земель, протест последнего может быть отклонен большинством бундестага (п.4 ст.77). В этих условиях земли потребовали, чтобы утрата их прав в ходе европейской интеграции была компенсирована участием в процессе принятия решений. Основы такого участия заложены в Законе о Едином европейском акте от 28 февраля 1986 г. В соответствии с этим законом бундесрат имеет право высказывать свое мнение по вопросам, входяшим в исключитељную компетенцию земель или затрагиваюшим их существенные интересы, до принятия решения федеральным правительством, которое должно учитывать это мнение ${ }^{10}$. Кроме того, с целью получения информации земли учредили свое представительство в Брюсселе.

Во Франиии, стране классического унитаризма, регионы (созданы в соответствии с Законом от 2 марта 1982 r.) могут заключать соглашения с приграничными регионами соседних стран. Отношения регионов с ЕС опосредованы: они осуществляются через комиссаров республиками и правительством, которое информирует постоянного представителя Франции в Брюсселе. В целом полномочия регионов в международной сфере не урегулированы, а существуюшие положения толкуются ограничителњно 11.

Несколько больше прав имеют области в Италии. Они располагают собственными законодательными и исполнительными учреждениями, однако судебная система находится полностью в ведении центра. Международные связи Италии принадлежат к исключительной компетенции государств. И лишь Конституционный суд в решении № 179 от 22 мая 1987 г. смягчил это положение, признав за областями право осуществлять деятельность международного значения ${ }^{12}$. Но и в этом случае требуется одобрение со стороны центрального правительства.

Автономные сообщества (регионы) Испании занимают по объему своих полномочий промежуточное положение межпу итальянскими областями и германскими землями. Конституция 1978 года вообще не упоминает о международной компетенции сообществ: международные договоры заключает тољько государство. Автономные сооб- 
щества имеют в Брюсселе информационное бюро, но, как и земли

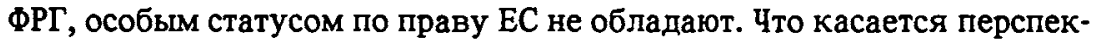
тив федерализации государственного устройства Испании, то Конституция дает на это четкий ответ: "Ни в коем случае не допускается федерация автономных сообшеств" (п.1 ст. 145).

Краткий обзор конституционно-правовой практики некоторых стран - членов ЕС позволяет сделать вывод о том, что идеал "Европы регионов" еще весьма далек от воплощения в жизнь. Основой объединения Европы в рамках ЕС остается деятельность национальных государств. Но возрастание роли регионов налицо, и оно находит свое выражение в деятельности как EC (решение о создании Совета региональных и локальных образований с совещательными функциями, принятие в 1988 г. Хартии регионализма), так и Совета Европы (разработка Хартии языков регионов и меньшинств).

Подписание договоров о политическом и валютно-финансовом союзе стран - членов ЕС (Маастрихт, 11 декабря 1991 г.) и связанные с ними перспективы усиления Европарламента с новой актуальностью ставят вопрос о правовой природе будущего Европейского союза - будет ли он федерацией, конфедерацией или международной организацией.

Общепризнанное определение федерации как "союза государств, обладающего постоянными общесоюзными органами власти и управления, выступающего в качестве единого субъекта международного права"13, как это ни парадоксально, не выявляет качественной специфики федерации по отношению к международной организации. Действительно, последняя также является субъектом международного права и представляет собой союз государств, которые, как и субъекты федерации, могут иметь больший и меньший объем международной правоспособности по вопросам, отнесенным к ведению союза.

В доктрине широко распространено мнение о том, что конфедерация и международная организация основаны на международных договорах, а федерация является государственно-правовым образованием ${ }^{14}$. Сушествуют, однако, исторические примеры, показывающие, что и федерация может быть образована на международноправовой основе: так, путем заключения договора были созданы Северогерманский союз в 1867 году, Советский Союз в 1922 году, путем присоединения одного государства к другому были образованы Королевство Югославия в 1918 году (к Сербии присоединились Черногория и территории, входившие в состав Австро-Венгрии, Хорватия, Словения, Далмация, Босния и Герцеговина, Воеводина) и Германия в 1990 году (ГДР присоединилась к ФРГ на основе решения Народной палаты ГДР). 
В принципе свобода усмотрения (автономия воли) сторон позволяет сделать предметом договора практически любой вопрос, представляющий взаимный интерес. Так, многочисленные договоры имеют свомм предметом отношения не только международного публичного, но и частноправового характера. В силу этого нет юридических препятствий для заключения договора между двумя и более государствами 06 образовании федеративного или даже унитарного государства.

Существует также точка зрения, что федерашия отличается от международной организации большей степенью централизации функций ${ }^{15}$, иными словами, более широкой компетенцией союза по сравнению с его составными частями. По нашему мнению, это чисто количественный подход, не выражаюший качественной спещифики рассматриваемых явлений.

Очевидно, что для разрешения проблемы необходимо выявить объективный качественный критерий, в котором воплощена воля учредителей по поводу создания федеращии или международной организация. На наш взгляд, таким определяющим критерием служит не источник (договор или конститущия) и не объем полномочий союза, а механизм их осуществления - система организации власти.

В этом случае отправным пунктом должно стать исследование природы законодательного органа или, в более широком плане, органа, принимающего решения, выполняемые иными звеньями союзной структуры. Представительство населения в таком органе указывает на федеративный характер образования. В противном случае союз является либо конфедерацией, либо международной организацией. Несмотря на то, что Европарламент представляет население EC, он полность лишен законодательных полномочий: статъя 137 Римского договора определяет его полномочия как "консультативные и контрольные". Кроме того, в ЕС отсутствует единый закон о выборах в Европарламент, и страны-участницы имеют свои квоты представительста: ФРГ, Франция, Италия, Великобритания по 81 депутату, Нидерланды - 25 и т.д. ${ }^{16}$ По этим причинам преждевременно говорить о создании "Соединенных ІІтатов Европы"; их возникновение связано лишь с формированием полноценной представительной системы.

В отличие от автономий, субъекты федерации являются государственными образованиями и имеют свою систему высших органов власти, управления и суда (возможны и исключения: так, земли Австрии не имеют своих судов). Признание их субъектами международного права и объем их прав и обязанностей зависят исключительно от норм внутригосударственного права. Видимо, нет юридических оснований считать невозможным одновременное наличие междунаропной правосубъектности и у членов федерации, и у центра. 
Итак, исходя из высказанных соображений, можно определитъ федерацию как союз государств, в законодательном органе которого представлено население союза. При этом представительство субъектов федерации, будучи закономерным, не является, тем не менее, абсолютно необходимым. Так, Конституция Югославии 1921 года предусматривала создание однопалатного парламента (без верхней палаты).

Что касается конфедерации, то по своей природе она сходна с международной организаџией: в ее основе лежит международный договор; она создается для определенных целей - как правило, для проведения общей внешней политики (так, потребность в совместной обороне стала главной причиной возникновения швейцарской конфедерации в 1291 г., конфедерации американских штатов в 1781 г, германской конфедерации в 1815 г.); в руководящем органе не представлено население союза.

Конфедерация, как правило, является переходной стадией объединения государств и завершается обьгно либо распадом союза, либо созданием федерации. При этом переход к федерации знаменуется прежде всего появлением нижней палаты парламента. На́пример, после поражения Австрии в австро-прусской войне 1866 года распалась германская конфедерация, и в 1867 году был основан Северогерманский союз, парламент которого состоял из рейхстага, избираемого населением (в конфедерашии он отсутствовал), и бундесрата, представляюшего государства.

Признание международной правосубъектности за конфедерацией зависит исключительно от воли ее создателей.

Завершая краткий обзор путей и средств формирования европейского единства, можно сделать вывод о том, что идея "общеевропейского дома" не является утопией, как полагают некоторые авто$\mathrm{pы}^{17}$, более того, юридически это вполне достижимо на основе формирования представительной системы в Европе и создания европейской федерации. Главное препятствие на пути строительства "общего дома" заключается в неравенстве уровней экономического развития разных стран. Лишь ликвидация этого неравенства откроет путь $к$ политическому объединению континента.

1 Авдресва и.С. Проблема мира в западноевропейской философин. M., 1975. - C. 237-238.

2 См. Беляев C.A. O концепции "европейского правового пространства"// Сов. государство и право. - 1991. - No 7. - С. 120; Резнпк А.В. Формирование европейского правового пространства (некоторые проблемы)// Сов. журнал междунаропного права. - 1991. - No 1. - C.46.

3 С.. Pesinir A.B. Указ. соч. - C.47.

4 CM. Bonnefous E. L' Europe en face de son destin. - P., 1955. - P.165. 
5 См. Энтв М.Л. Суд Европейских сообществ. Правовые формы обеспечения западноевропейской интеграпии. - М., 1987. - С.37-76.

6 См. подробно: Крнлова и.С. Европейский парламент (правовой статус). - M., 1987.

7 Процессы, идушие в бывшем Советском Союзе, Чехо-Словакии и Югославии, связаны с появлением новых независимых государств и поэтому заслуживают отдельного рассмотрения.

8 См. Пустотаров В.В. Общеевропейский процесс и проблемы федерализма//Сов. государство и право. $-1991 .-N^{\circ} 6 .-$ С. 29-30.

9 Tan ze. - C. 38.

$10 \mathrm{CM}$. Föderalismus und Regionalismus in Europa // Verfassungskongre in Bonn rom 14-16 September 1989. Fritz Ossenbuiil (Hrsg.) - Baden-Baden, 1990. S.148.

11 Ibid. - S.219.

12 Ibid. - S.258.

13 Cповарь мехиународного права. - M., 1986. - C. 409.

14 CM. Hay P. Federalism and Supranational Organisations. Patterns for new Legal Structures.- Univ. of Illinois Press, 1966. - P.87.

15 Kelsen H. Principles of International Law. - N.Y., 1952. - P.101; Bindschedler R.L. Rechtsfragen der europäischen Einigung. - Basel, 1954. - S.33.

16 См. Хиршлер М., Циогерман Б. Западноевропейские интеграционные объединения. Право. - М., 1987. - С.53.

17 См. например, Иљин ю.Д. Обустроит ли международное право современный мир? // Сов. журнал международного права. - 1991. - N¹. - C.123. 